\title{
Embankment dam leakage survey based on ERI and MRS
}

\author{
LI Hongen ${ }^{1, ~ a ~, ~ L I ~ Z h e n g ~}{ }^{1, ~ b}$, XU Haifeng ${ }^{1, ~ c}$, He Yongjun ${ }^{1, d}$ \\ 1 Dam Safety Management Department, Nanjing Hydraulic Research Institute, Nanjing 210029, \\ P. R. China \\ aheli@nhri.cn, blizheng@nhri.cn,chfxu@nhri.cn, dyjhe@nhri.cn
}

\begin{abstract}
Keywords: Leakage survey; Embankment; Magnetic resonance sounding; Electrical resistivity imaging

Abstract. Embankment dam leakage may cause devastating consequences and its early detection plays a significant role in the stability of embankment dam. Conventional dam leakage detection methods, such as piezometric tube or osmometer, are restricted by limitations of spatial distribution and high costs of instruments. This paper introduces the method of joint use of Magnetic Resonance Soundin(MRS) and Electrical Resistivity Imaging(ERI) to investigate embankment dam leakage. MRS and ERI are carried out to reveal embankment dam leakage in the same site and the stratigraphy of electrical conductivity obtained by ERI is carefully used for the inversion process of MRS data. And then the amount of groundwater in the subsurface can be directly determined by the technique of MRS. The MRS and ERI results show good consistency with yield data obtained by geological survey. Finally, the detecting capability of joint use of MRS and ERI is verified.
\end{abstract}

\section{Introduction}

Rapid detection of embankment dam seepage field and leakage risk is of great significance to prevent dam failure and other security incidents. Traditional methods to explore seepage field are piezometers, exploration well, isotopic tracer, ground penetrating radar, electrical resistivity imaging (ERI), etc. Since the resistivity of geotechnical materials is sensitive to water, non-destructive electrical resistivity imaging method has higher resolution in dam seepage diagnosis. For example, high-density resistivity method (an improved ERI method) holds the advantages as high data capacity, intuitive imaging and portable instrument (P. Sjödahl et al., 2008; M.H. Loke et al., 2013), which make it especially suitable for the rapid diagnosis of embankment dams leakage risks. The physical basis of seepage exploration with ERI method is detecting appearance of low resistivity anomalies when dam leakage occurs. However, geotechnical materials resistivity is influenced by soil properties, degree of weathering and other factors except water (P. Sjödahl, 2006; Seokhoon et al., 2008 ), therefore it's hard to obtain the determinants of low resistivity anomalies areas only by ERI method. Recently developed magnetic resonance sounding (MRS) method is a new direct way for groundwater exploration(PAN Yuling et al., 2004). MRS method utilizes the nature of proton relaxation differences between water proton and atomic nucleus of other substances. Rectangular alternating current pulse is emitted underground and signal is collected by the same antenna, then the moisture content, permeability, relaxation time and other parameters of the geotechnical materials could be achieved with proper inversion(LI Zhenyu et al.,2006; J.F. Girard et al.,2008; A. Legchenko et al., 2002; A. Guille et al.,2002). These characters make it possible to detect dam leakage risk by MRS method.

Based on a detailed site survey, we carry out the application study of joint use of MRS method and electrical resistivity imaging (ERI) method (Kamhaeng et al., 2008; J.M. Vouillamoz et al., 2007)to investigate the seepage field and leakage risk of a embankment dam. Taking the aquifer depth obtained by MRS method and combining the data by ERI, the electrical resistivity value of moisture soil is determined and the leakage channel inside dam is detected. Finally the detecting capability of joint use of MRS and ERI is verified. 


\section{Study area overview}

\section{Dam structure}

The type of dam in this study is compacted rockfill dam. The length of the dam axis is $230.0 \mathrm{~m}$, crest elevation is $1841.30 \mathrm{~m}$, and the maximum height is $35.3 \mathrm{~m}$. The typical cross-section of the dam structure is shown in Figure 1. The front part, filling with blended loam and weathered rock breccia, is located on the upstream side of the dam and the permeability coefficient $\mathrm{k}=3.4 \times 10^{-5} \mathrm{~cm} / \mathrm{s}$. The middle part, filling with loam, is located in the central area and $\mathrm{k}=1.52 \times 10^{-5} \mathrm{~cm} / \mathrm{s}$. The back part, filling with loam, breccia, pebbly loam and weathered rocks, is close to the middle part and $\mathrm{k}=6.2 \times 10^{-5} \mathrm{~cm} / \mathrm{s}$. Between the stack number $0+050$ and $0+170$, vertical and horizontal drainage system is set up in the middle and back part of the dam, aiming at reducing the dam phreatic line.

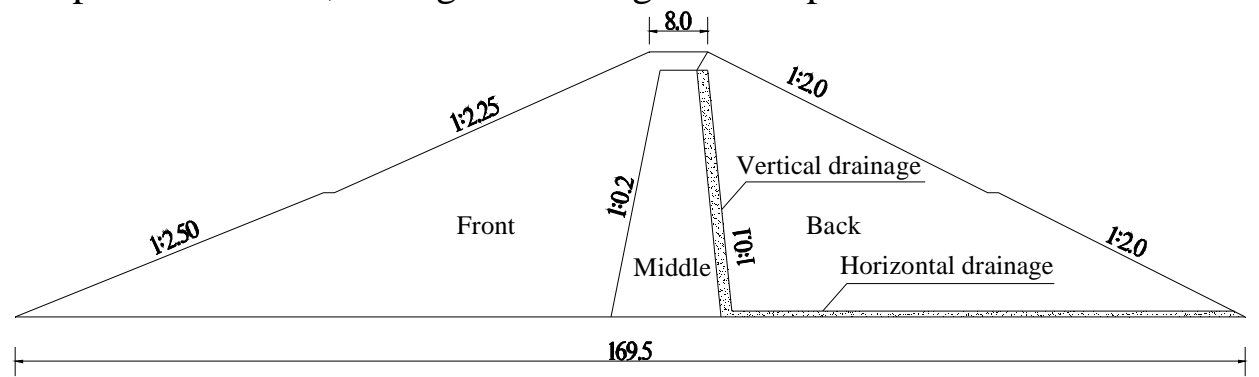

Figure 1 Typical cross-section of the dam structure

\section{Dam leakage}

During the common operation period of the project, leakage problems emerged on the downstream slope of the dam and the left abutment, location of dam leakage marked as region A is shown in Figure 2. Region A is located near the left abutment of the dam foot, the precise leakage scale of the region is below $1822.00 \mathrm{~m}$ elevation and between stake number $0+025$ and $0+057$. The present leakage flow of region A is $1.3 \mathrm{~L} / \mathrm{s}$. Signs of damage such as thaw slumping, longitudinal cracks and surface slide occur in region $\mathrm{A}$ at present, shown in Figure 3. Except region A, the phenomena of wetting soil on the downstream slope surface has been found near right abutment.

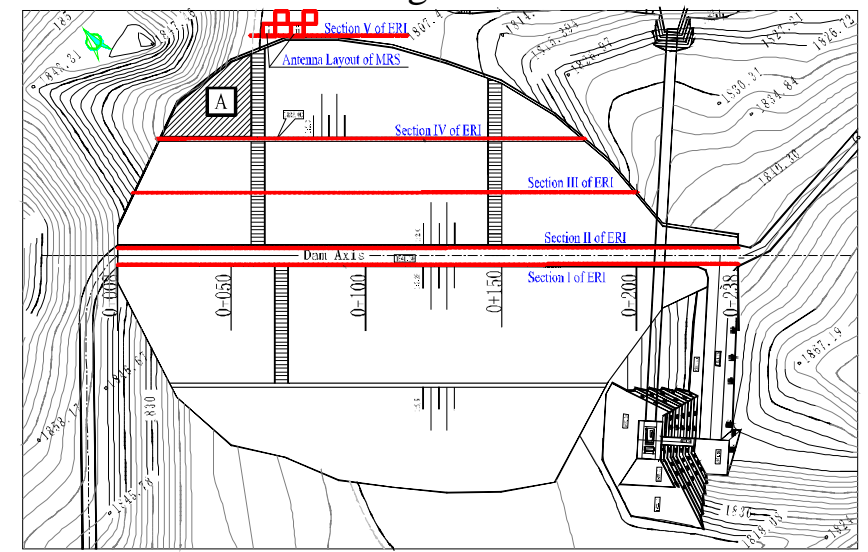

Figure 2 Location of dam leakage and detection layout of ERI and MRS

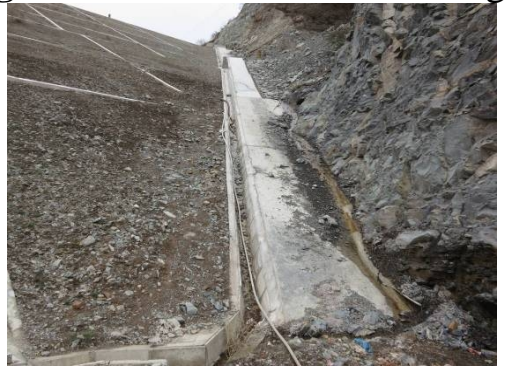

(a)

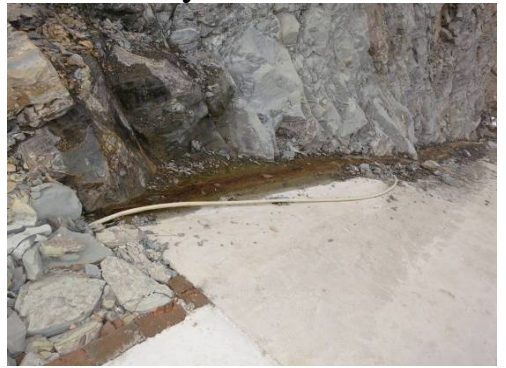

(b)

Figure 3 Location of dam leakage Region A (a)Leakage overview (b)Contact leakage between dam and abutment 


\section{Seepage and leakage survey}

\section{ERI method}

In order to detect the dam leakage, five detecting sections were set up parallel to dam axis direction from the dam crest to the downstream slope foot, seeing Figure 2. 'Pole-Pole' array was adopted to obtain sufficient detecting depth. The number of electrodes is 32 and the electrode spaces are from $2.2 \mathrm{~m}$ to $7.5 \mathrm{~m}$ according to the total length of the detecting section. Characteristics of all the detecting sections are summarized in Table 1.

Table 1 Characteristics of all the detecting sections

\begin{tabular}{|c|c|c|c|c|c|c|c|}
\hline \multirow{2}{*}{$\begin{array}{c}\text { No. of } \\
\text { detecting } \\
\text { section }\end{array}$} & \multirow[b]{2}{*}{$\begin{array}{c}\text { axle } \\
\text { base /m }\end{array}$} & \multirow[b]{2}{*}{ Elevation/m } & \multicolumn{2}{|c|}{ Stack Number/m } & \multirow[b]{2}{*}{$\begin{array}{l}\text { Electrode } \\
\text { array }\end{array}$} & \multirow{2}{*}{$\begin{array}{l}\text { Number of } \\
\text { Electrodes }\end{array}$} & \multirow[b]{2}{*}{$\begin{array}{c}\text { Electrode } \\
\text { space/m }\end{array}$} \\
\hline & & & $\begin{array}{c}\text { Starting } \\
\text { point }\end{array}$ & $\begin{array}{c}\text { Terminal } \\
\text { point }\end{array}$ & & & \\
\hline I & $0-004.0$ & 1841.30 & $0+008$ & $0+240.5$ & $\begin{array}{l}\text { Pole- } \\
\text { Pole }\end{array}$ & 32 & 7.5 \\
\hline II & $0+004.0$ & 1841.30 & $0+008$ & $0+240.5$ & $\begin{array}{l}\text { Pole- } \\
\text { Pole }\end{array}$ & 32 & 7.5 \\
\hline III & $0+021.3$ & 1832.65 & $0+014$ & $0+215.5$ & $\begin{array}{l}\text { Pole- } \\
\text { Pole }\end{array}$ & 32 & 6.5 \\
\hline IV & $0+040.1$ & 1822.00 & $0+024$ & $0+179.0$ & $\begin{array}{l}\text { Pole- } \\
\text { Pole }\end{array}$ & 32 & 5.0 \\
\hline $\mathrm{V}$ & $0+078.1$ & 1803.00 & $0+055$ & $0+123.2$ & $\begin{array}{l}\text { Pole- } \\
\text { Pole }\end{array}$ & 32 & 2.2 \\
\hline
\end{tabular}

The gross error detection, data inversion and post-processing are realized in Geotomo Software-Res2dinv 3.54 program. Forward calculation was carried out by Finite difference method. 4-node quadrilateral element was adopted and the mesh was encrypted properly, which is shown in Figure 4. Least squares optimization algorithm based on smooth inhibition was used to inverse the detecting data. Taking into account the great resistivity difference between dam rockfill and bedrock, the robust inversion method was utilized to reduce the influence of noise and to improve the inversion accuracy as well.

The inversion results of 5 detecting sections are shown in Figure 5. For interpretation convenience, abscissa is stack number with constant coordinate while ordinate is detecting depth with logarithmic coordinate.

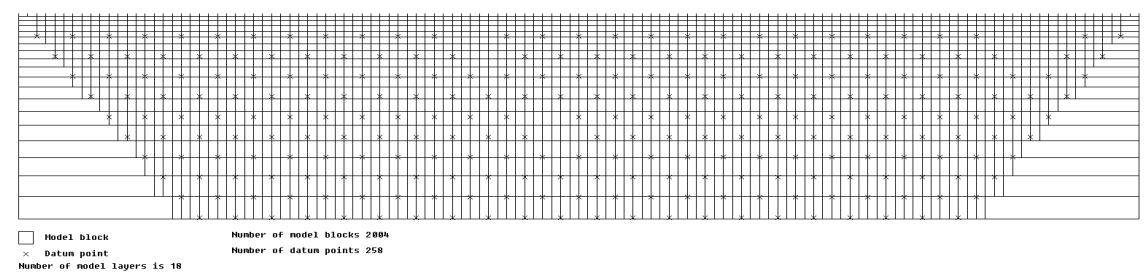

Figure 4 Finite difference method mesh of detecting sections 


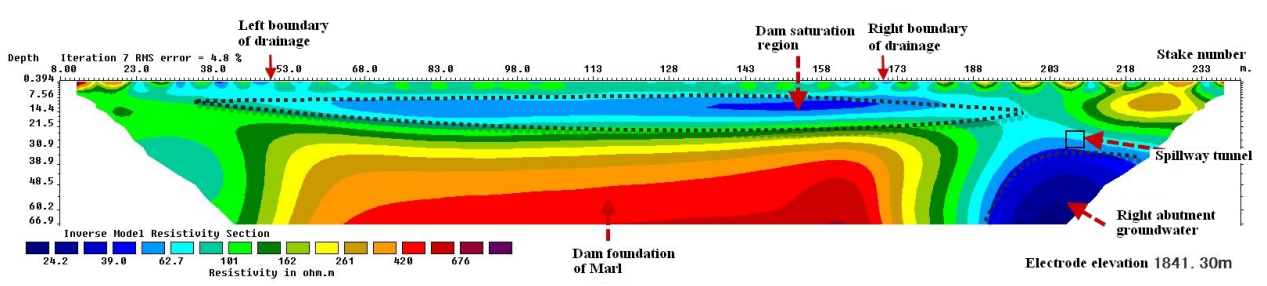

(a)

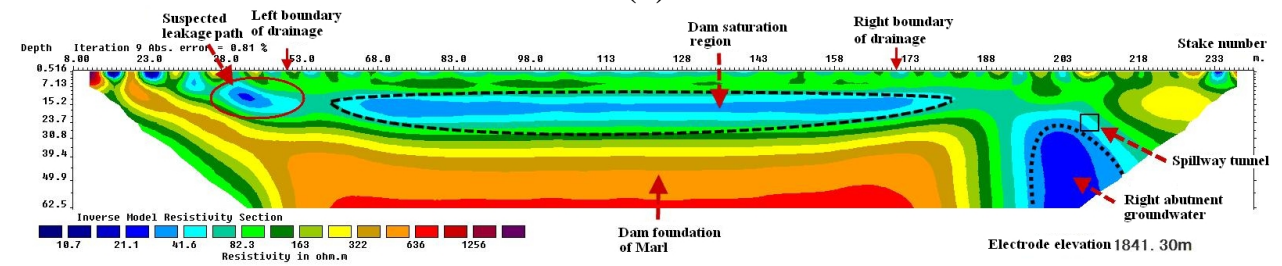

(b)

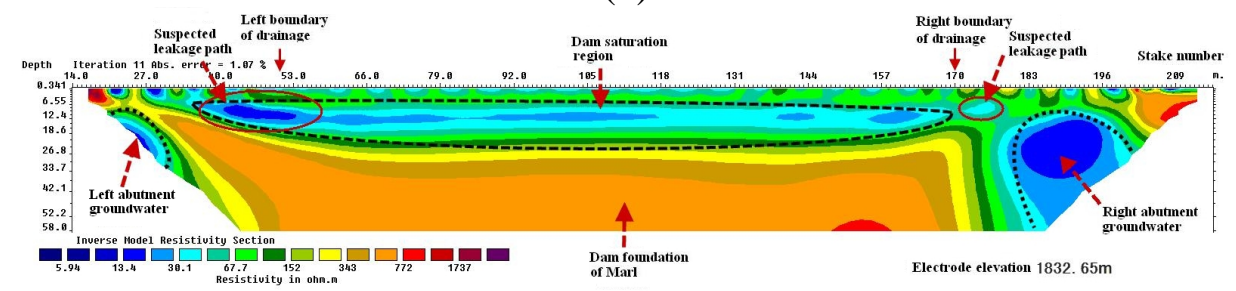

(c)

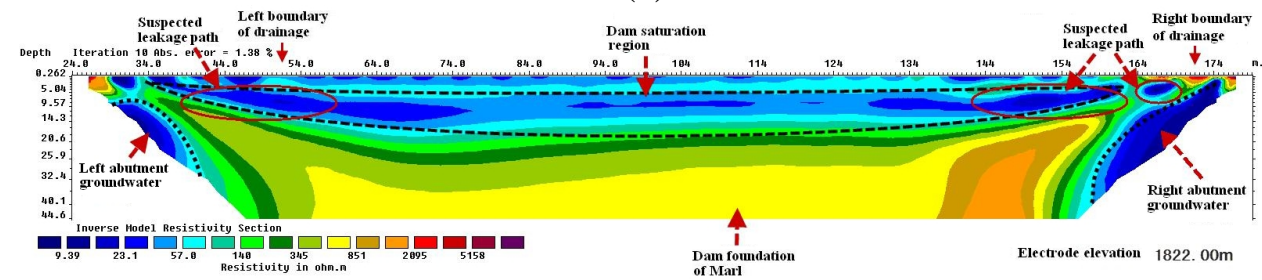

(d)

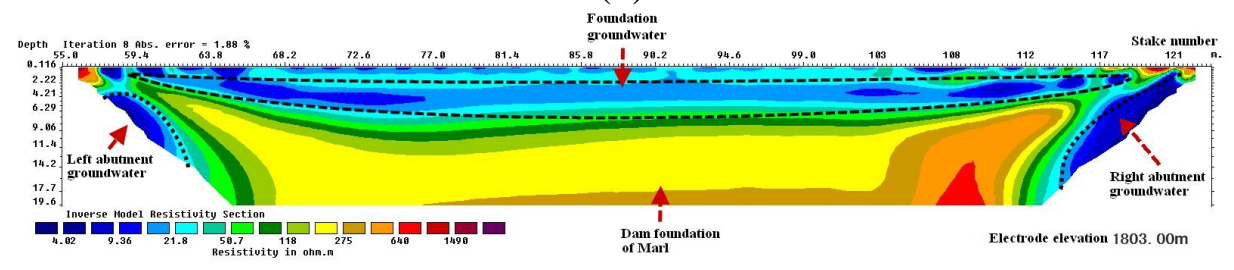

(e)

Figure 5 Inversion contours of resistivity (a) section I, (b) section II, (c) section II, (d) section IV, (e) section $\mathrm{V}$

\section{MRS method}

MRS method detection of the dam was realized by Numis Poly Multi-channel Magnetic Resonance System (Figure 6)and the detecting location is shown in Figure 2, which is aimed to get the seepage field distribution near dam foot. Geomagnetic field was measured by Numis magnetometer and Larmor frequency was calculated. To reduce the impact of environmental noise, the layout of eight-shaped double loop with $12 \mathrm{~m}$ side length for antennas was adopted, in addition, the antenna diagonal was set to be parallel to the adjacent powerline direction.

Considering the resistivity measured by high-density resistivity method detection, MRS detecting data is inversed by Samovar program supplied by Numis and the results are shown in Figure 7. 


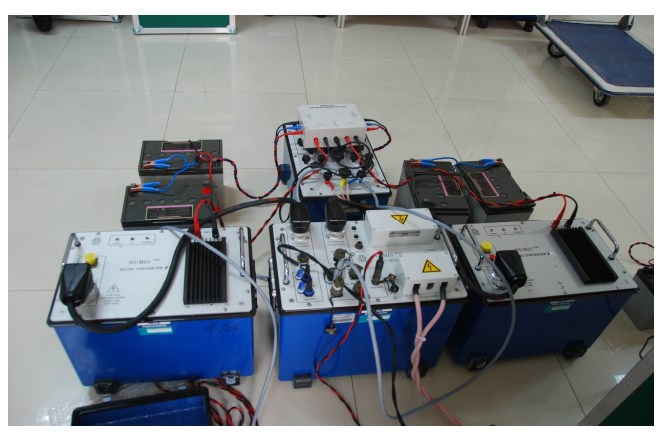

Figure 6 Numis Poly Multi-channel Magnetic Resonance System(MRS)

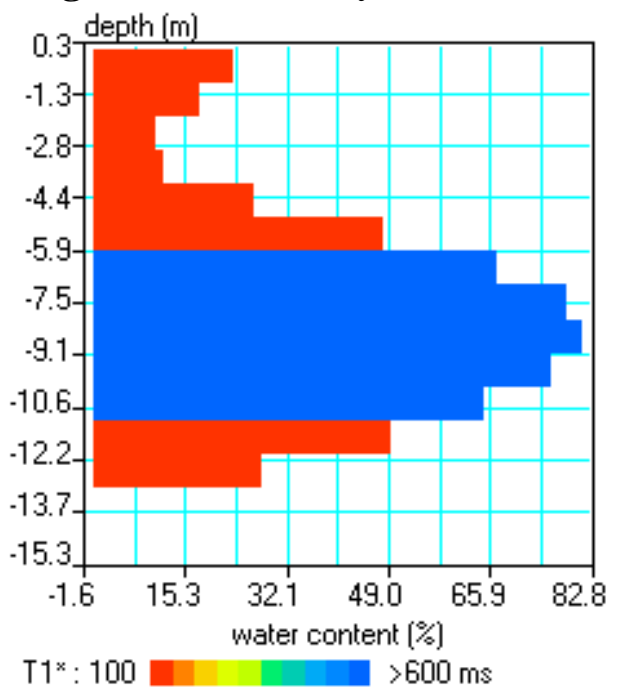

(a)

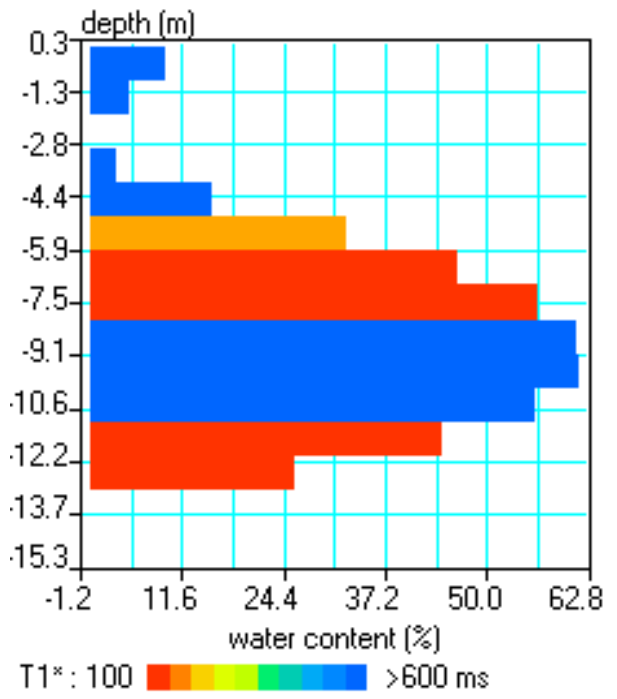

(b)

Figure 7 MRS inversion results (a) close to left abutment, stack No.: 0+060-0+084; (b)close to original river channel

\section{Detection results interpretation}

\section{MRS results interpretation}

From Figure 7, two groups of the MRS inversion results show almost same changing patterns in water content along depth direction. The water content values of the soil layer with the depth of $0 \sim 3 \mathrm{~m}$ are quite lower, that are $5 \%$ to $20 \%$, while in the deeper layers with the depth of $5 \sim 11 \mathrm{~m}$, the water content values are much larger and their maximum values even reached $80 \%$ and $60 \%$ separately. Through the boring geological survey data that the sorts of detected layers are strongly or weakly weathered marl, and considering the low resistivity anomalies areas near left abutment in the Figure 5(e), inversion results of MRS and ERI match well. Comparing Figure 7(a) and (b), the water contents of aquifer close to left abutment are commonly larger than the aquifer near the middle dam foot with the amplitude of $10 \%$ to $20 \%$. The reason of this phenomenon is due to the existence of leakage channel through the dam close to left abutment and consequently large amount of leakage flow.

\section{ERI method results interpretation}

From the numerical inversion of resistivity contour of five detecting sections, the resistivity distributions of dam, foundation and abutments were revealed well by high-density electrical method. Based on the saturation criterion aforementioned, the ERI results are interpreted in the following part.

The detecting section I in Figure 5(a) is located on the top of dam with elevation $1841.30 \mathrm{~m}$ near upstream side and its axle base is $0-004 \mathrm{~m}$. The detecting scale ranges from stack number $0+008 \mathrm{~m}$ to $0+240.5 \mathrm{~m}$. The section cut off the front and middle part of dam body shown in Figure 4 and is the largest dam section in longitudinal direction. The resistivity of complete marl in central dam foundation is generally greater than $261 \mathrm{ohm} \bullet \mathrm{m}$, but in the right and left abutment there are large scales of low 
resistivity zone, which has been revealed as strongly weathered marl of strong permeability by prior geological survey. The resistivity of unsaturated dam is in the range of $70 \sim 100 \mathrm{ohm} \cdot \mathrm{m}$ and the resistivity of the saturated dam body decreased significantly. Since the section is located in front of the dam vertical and horizontal drainage system, the saturation region is uniform and there are no obvious abnormalities in the section.

The resistivity inversion results of section II are shown in Figure 5(b), whose distribution is similar to section I. There is a wide range of low resistivity zone on the right abutment, which indicates that the strong permeable layer distributes continuously the downstream side. The resistivity of unsaturated dam in section II is in the range of $82 \sim 163 \mathrm{ohm} \bullet \mathrm{m}$. Comparing to the measuring points with the same elevations in section I, resistivity in this section become higher, which means the dam phreatic line is decreasing progressively. Meanwhile, a low resistivity anomaly zone with stack number of $0+028-0+053 \mathrm{~m}$ first appears close to left abutment, which is speculated as the leakage source corresponding to the anomalies in Figure 3.

Detecting section III is located on the downstream slope with the elevation of $2 / 3$ maximum dam height, whose resistivity distribution is shown in Figure 5(c). The resistivity of consecutive and complete Marl in dam foundation is generally greater than $343 \mathrm{ohm} \cdot \mathrm{m}$. There is a wide anomaly zone of low resistivity in right abutment with the distribution shape of closed ellipse, which is consistent to the presence of strongly weathered and permeable rock revealed by geological survey. The low resistivity anomaly zone appearing in detecting section II is developing continually in this section, with perforation to the lateral normal saturated soil region. The resistivity inside the anomaly zone is significantly lower than the saturated dam soil, which indicating the deterioration of the leakage channel. New low resistivity anomaly zone appears in dam body close to right abutment with stack number of $0+171-0+177 \mathrm{~m}$, which is suspected as the leakage source corresponding to the leakage anomalies at dam site.

Detecting section IV in Figure 5(d) is located on the downstream berm and is very close to the leakage area in Figure 6. The inversed resistivity in anomaly zones of the section becomes much lower than them in all the sections aforementioned, which indicating confirmation of the export of the leakage channel.

Detecting section IV locating near the dam foot exposed the resistivity distribution of the dam foundation. The section is regarded as a reference and analysis basis for MRS interpretation which has been mentioned in the discussion part of MRS results.

\section{Conclusions}

In our work, the possibility of joint application of MRS and ERI methods for dam seepage field detection is verified. The two complementary methods could supply a rapid diagnose way to investigate seepage characters of rockfill dam and the locations of abnormal leakage, which is meaningful to timely determination of leakage cause and the emergency treatment for the dam stability.

The water distribution aquifer obtained by MRS method is in the form of volumetric water content. There is a problem of low resolution when MRS method is independently applied to the seepage detection of dams. Correspondingly, multiple solutions of interpretation induce the difficulty to obtain accurate distribution of groundwater and rock permeability solely using the ERI method. Therefore, joint use of MRS and other ERI methods to investigate embankment dam seepage field is a good way to solve the problem. When detecting the seepage field by joint application of MRS and ERI methods, the mutual relationship is significant. The MRS method can accurately obtain the distribution of groundwater in form of volumetric content, which will be the effective analysis foundation for ERI method. Meanwhile, the successive resistivity distribution gained by ERI method could conquer the low resolution problem of MRS method. 


\section{Acknowledgements}

This work was financially supported by the National Natural Science Foundation of China (51309164,51579154), Research Projects in Public Interest of Ministry of Water Resources (201301033) , the National Key Technology Research and Development Program of the Ministry of Science and Technology of China (2012BAK10B04), the Natural Science Foundation of Jiangsu Province of China (BK20130072), and the Fundamental Research Project of Ministry of Water Resources(Y715015).

\section{References}

[1] P. Sjödahl, T. Dahlin, S. Johansson, M.H. Loke. (2008): Resistivity monitoring for leakage and internal erosion detection at Hällby embankment dam, Journal of Applied Geophysics, 65, pp.155-164, Elsevier, Stockholm, Sweden.

[2] M.H. Loke, J.E. Chambers, D.F. Rucker, O. Kuras, P.B. Wilkinson.(2013): Recent developments in the direct-current geoelectrical imaging method, Journal of Applied Geophysics, 95, pp.135-156, Elsevier, Stockholm, Sweden.

[3] P. Sjödahl. (2006): Resistivity investigation and monitoring for detection of internal erosion and anomalous seepage in embankment dams, Doctoral Thesis, Lund University, Sweden.

[4] Seokhoon Oh, Chang-Guk Sun. (2008): Combined analysis of electrical resistivity and geotechnical SPT blow counts for the safety assessment of fill dam, Environmental Geology, 54, pp.31-42, Springer, Heidelberg, Germany.

[5] PAN Yuling, J. Bernard, LI Zhenyu, et al. (2004): Introduction of new hydroscope and its application to embankment monitoring, China Dam Safety, 1, pp.27-29, Hangzhou, China.

[6] LI Zhenyu, KANG Minghui, PAN Yuling.(2006): Application of MRS in Geology Engineering, China University of Geosciences Press, Wuhan, China.

[7] J. F. Girard, A. Legchenko, M. Boucher, J.-M. Baltassat. (2008): Numerical study of the variations of magnetic resonance signals caused by surface slope, Journal of Applied Geophysics, 66, pp.94-103, Elsevier, Stockholm, Sweden.

[8] Legchenko, P. Valla. (2002): A review of the basic principles for proton magnetic resonance sounding measurements, Journal of Applied Geophysics, 50(1), pp.3-19, Elsevier, Stockholm, Sweden.

A. Guillen, A. Legchenko. (2002): Application of linear programming techniques to the inversion of proton magnetic resonance measurements for water prospecting from the surface, Journal of Applied Geophysics, 50, pp.149-162, Elsevier, Stockholm, Sweden.

[9] Kamhaeng Wattanasen, Sten-Åke Elming. (2008): Direct and indirect methods for groundwater investigations: A case-study of MRS and VES in the southern part of Sweden, Journal of Applied Geophysics, 66, pp.104-117, Elsevier, Stockholm, Sweden.

[10]J.M. Vouillamoz, B. Chatenoux, F. Mathieu, J.M. Baltassat, A. Legchenko. (2007): Efficiency of joint use of MRS and VES to characterize coastal aquifer in Myanmar, Journal of Applied Geophysics, 61, pp.142-154, Elsevier, Stockholm, Sweden. 